\title{
The Education Cloud Platform for Digital Resources with Block Chain under Intelligent Learning Environment
}

\author{
Chen Li \\ No. 1 Middle School Affiliated to Central China Normal University, Wuhan, China \\ Email:273722307@qq.com
}

How to cite this paper: Li, C. (2022). The Education Cloud Platform for Digital Resources with Block Chain under Intelligent Learning Environment. Creative Education, 13, 599-608.

https://doi.org/10.4236/ce.2022.132036

Received: January 20, 2022

Accepted: February 19, 2022

Published: February 22, 2022

Copyright ( 2022 by author(s) and Scientific Research Publishing Inc. This work is licensed under the Creative Commons Attribution International License (CC BY 4.0).

http://creativecommons.org/licenses/by/4.0/

\section{(c) (i) Open Access}

\begin{abstract}
The education cloud platform has developed the education cloud standard specification system, which has laid the foundation for the establishment of the cloud public service system. It has developed the education cloud basic support, conquered the relevant key technologies of education cloud services, modeled the education cloud green security service guarantee, and built a safe and reliable education cloud public service. Infrastructure is the foundation of the environment; without infrastructure, there is no ecological soil for growth. The most difficult thing about the combination of education and technology is that the integration itself is an integration of value orientations. The overall structure is based on the structure of the blockchain, which is designed according to the security needs of digital educational resources. Under the premise of solving the problem, it can design and implement the operation of forming a chain of data blocks, so as to solve the problem of data asynchrony.
\end{abstract}

\section{Keywords}

Education Cloud Platform, New Infrastructure, Digital Core, Digital Transformation, Block Chain

\section{Introduction}

Forming a multi-layer education cloud service platform integration framework of infrastructure, resource integration and service integration are integrated with the use of cloud computing and virtualization (Nie et al., 2018; Mkrttchian et al., 2014; Cornetta, 2019). This is to achieve transparent management of computing, storage, and network equipment, in terms of meeting the needs of massive high-quality educational resources (Masud et al., 2012; Ju \& Shen, 2011; Ezen- 
woke et al., 2013). Basic requirements involve storage, access, and analytical processing (Wu et al., 2021; Gu et al., 2021). It integrates high-quality educational resources, establishes an educational cloud service model and a co-construction and sharing mechanism, conducts large-scale application demonstrations, improves the service and application model of educational cloud, promotes the deep integration of education and cloud technology, and drives the development of modern education service industry (Simões \& Soares, 2019; Abdullayev, 2020).

It has practiced a variety of applications in space application, teaching application, teaching and research application, etc. It formed an intensive way of resource allocation and service, which can provide applicable, flexible and diverse resource applications and services, and promote the use of education cloud and contiguous applications across the country, normalized application and effective application, forming a teaching and teaching and research model in the information environment that different regions and schools can learn from (Dwivedi et al., 2020; White, 2018; Kudinov et al., 2018).

Education has traditional infrastructure. For example, the traditional infrastructure of a school includes school classrooms, libraries, laboratories, playgrounds, canteens (Park et al., 2018; Kweon et al., 2021; Winkler \& Söllner, 2018). Walking into each classroom also includes desks, blackboards, chalks, projectors, whiteboards, teaching materials, stationery, etc. A series of standard processes and mechanisms are also hidden behind traditional infrastructure (Alshare et al., 2018; Zamora-Polo et al., 2019; Rustamova, 2019). That is to say, many things in traditional education infrastructure have their own structures and processes (Sheikh \& Fann, 2019; Lergetporer et al., 2018).

\section{New Education Infrastructure}

\subsection{Back-to-Reality Design}

The import and export bandwidth of many schools claims to be gigabit to the school and gigabit to the classroom. Indeed, over the past ten years, we have invested human, material, and financial resources, and have achieved phased progress in the three links and two platforms, with a high network penetration rate and steady improvement in hardware and software equipment. However, what we want today is not only to meet the network needs of teachers in schools, but also to meet the new needs of students for online and offline integrated teaching, and to explore new needs for realizing large-scale personalized education.

Often many schools that have the courage to explore educational informatization have to find other ways to solve network problems. This phenomenon has been a problem for a long time. Facing the new infrastructure of education, we need to rearrange the layout and solve these bottom-level problems in order to fully empower the systematic development and structural adjustment of education.

\subsection{Five Aspects of New Educational Infrastructure}

Network-based communication is only one aspect. Educational resources, smart 
terminals, data centers, and educational applications all constitute some of the necessary foundations for new educational infrastructure. The new infrastructure for education includes at least five basic parts: network communication foundation, intelligent terminal foundation, education resource foundation, data center foundation, and education platform foundation. Educational resources are not digital resources of textbooks in the past, nor teachers' lesson plan library or PPT resource, but digital resources suitable for students' learning, and a new interactive resource system that can provide students with learning activities, learning evaluation, and learning guidance.

The intelligent terminal is not only the teacher's terminal, but also the student's terminal, which supports students to participate in learning and carry out learning. The data center is not the static data of the learning archives, but the dynamic data of the students' learning process. A data center can't just collect, not categorize, nor analyze. Data centers need to be embedded with intelligent analytics.

The foundation of the education platform is not a fragmented website platform or application, but a new platform that can support teachers and students to carry out online and offline integrated education. There can be many applications, many interfaces, and many functions, but they are not fragmented or customized, but a systematic and optional basic platform.

The new infrastructure for education cannot be achieved at one touch. To a certain extent, it is also difficult to rely on the personalized customization of one or several schools for development. Instead, it is necessary to form a continuous iterative student to jointly promote the healthy development of educational technology. No industry will break the traditional infrastructure and build new infrastructure. The same goes for the education industry. Figure 1 shows the cloud system with block chain under different applications.

\subsection{Combination of Education and Technology}

Education has traditional infrastructure. For example, the traditional infrastructure of a school includes school classrooms, libraries, laboratories, playgrounds, canteens, etc. Walking into each classroom also includes desks, blackboards, chalks, projectors, whiteboards, teaching materials, stationery, etc.

A series of standard processes and mechanisms are also hidden behind traditional infrastructure. For example, the textbooks are developed and compiled according to the national curriculum standards, which need to be reviewed by the National Textbook Committee, and then through a series of teacher training and teaching research, so that the curriculum can be implemented in the classroom. That is to say, many things in traditional education infrastructure have their own structures and processes.

It is precisely because we are facing an information age and entering the age of intelligence, our education must keep pace with the times, and our students must develop the knowledge, ability and literacy to face future challenges in school. 


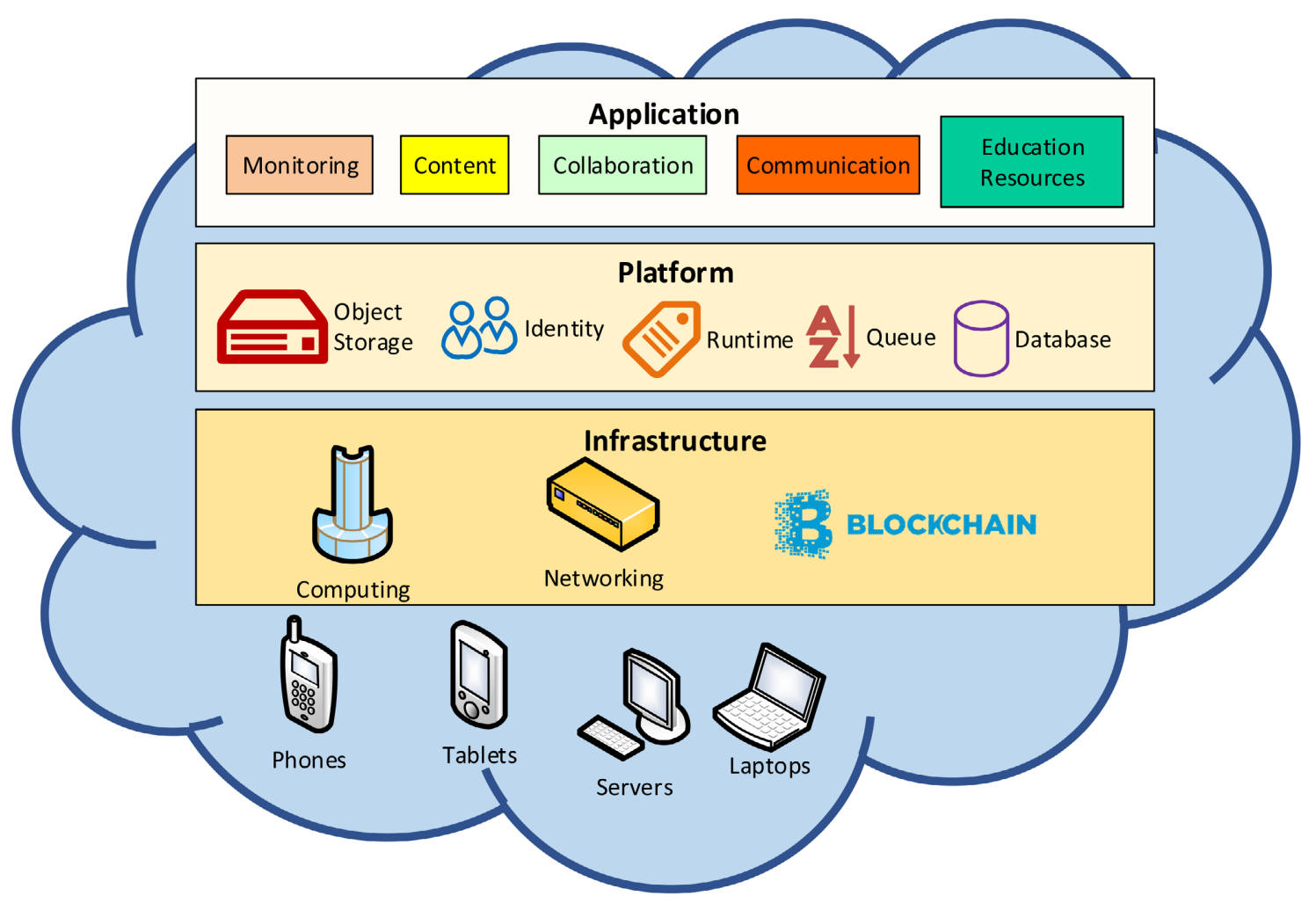

Figure 1. Cloud system with block chain under different applications.

According to the documents issued by the Political Bureau of the Central Committee of the People's Republic of China, the construction of new infrastructure, i.e., new infrastructure, has been explained as focusing on seven areas, including: 5G, artificial intelligence, industrial Internet, big data centers, new energy, Intercity expressway and rail transit. Closely related to the new infrastructure for education are: 5G, artificial intelligence, and big data centers.

The learning mechanism behind each structural design may be different. The orientation of the platform designer to develop the design determines the value of its education. The new infrastructure for education cannot be achieved at one touch. To a certain extent, it is also difficult to rely on the personalized customization of one or several schools for development. Instead, it is necessary to form an iterative ecology to jointly promote the healthy development of educational technology. No industry will break the traditional infrastructure and build new infrastructure.

\section{Driving the Transformation and Upgrading of Traditional Education}

Judging from the current situation, now is a good opportunity to promote the construction of new infrastructure. Regardless of technology level or business model, it provides good conditions for the construction of new infrastructure. At the same time, the development of new infrastructure will also counteract technology and commerce, promote technological progress, promote business model 
innovation, prompt a huge change in consumption habits, and enable infrastructure and industry to form a positive interaction.

The role of infrastructure to make up for shortcomings is similar to that of traditional infrastructure, which can directly drive the development of rail transit, medical care, public facilities and other industries, and indirectly promote the development of construction machinery, cement building materials and other industries. For the construction of transportation, rural infrastructure and public service facilities, new infrastructure also has the function of making up for shortcomings. It can not only drive the development of rail transportation, medical care, old-age reform, cultural and sports industries, etc., but also transmit through the industrial chain, bringing development opportunities to upstream industries such as construction, construction machinery, and cement building materials.

In a narrow sense, new infrastructure refers to the construction of $5 \mathrm{G}$, big data, artificial intelligence, industrial Internet and other projects. The key is to promote the transformation and upgrading of traditional industries in the direction of digitization, networking and intelligence. Based on this feature, the new infrastructure can not only directly promote the development of related industries, but also drive the development of upstream and downstream industries, benefiting industries such as electronic information equipment manufacturing, information transmission services, and software information technology services.

\subsection{Digital Infrastructure as the Core}

From a qualitative point of view, the new infrastructure represented by 5G, artificial intelligence, industrial Internet, and the Internet of Things is digital infrastructure and is an important foundation for the realization of the strategy of digital power.

With the rapid development of the Internet of Things, the era of Internet of Everything is gradually approaching, and there are more and more connected terminals, and the scale of data generated is getting larger and larger. Under this situation, the digital economy supported by new-generation information technologies such as cloud computing, big data, artificial intelligence, Internet of Things, and blockchain has entered the fast lane and is developing faster and faster. However, in order for the digital economy to develop steadily and achieve the strategic goal of building a digital power, a complete set still needed. Therefore, the construction of new infrastructure should be based on the construction of digital infrastructure.

In order to optimize resource allocation and improve the quantity and quality of economic growth, my country has begun to implement supply-side structural reforms. Under this situation, the desire of traditional industries to change the original development model and develop towards digitalization and intelligence becomes more and more urgent. For traditional industries in the transition period, 5G, Internet of Things, artificial intelligence and other new infrastructure 
centered on digitalization provide strong support.

For example, the construction of the Industrial Internet can promote the transformation of traditional manufacturing to digital manufacturing and intelligent manufacturing; the construction of Internet of Vehicles, energy Internet, and intelligent transportation infrastructure can promote the development of new energy vehicles and intelligent connected vehicles; the construction of urban Internet of Things can help promote the transformation of urban public infrastructure such as water, electricity, and gas to digitalization and intelligence; the agricultural Internet of Things can provide strong support for the development of smart agriculture. Figure 2 shows a cloud for education with different interactions under new infrastructure.

\subsection{Key Points of New Infrastructure Construction}

According to the requirements of the National Development and Reform Commission, in the next few years, infrastructure construction must adhere to the principle of the troika. In the construction of rural infrastructure, the third is to do a good job in the construction of major infrastructure such as energy, transportation, and water conservancy. In order to give full play to the investment efficiency, it is necessary to correctly handle the relationship between the new infrastructure construction and the traditional infrastructure construction, and do a good job in the integration and transformation of the two.

For example, $5 \mathrm{G}$ construction can use $4 \mathrm{G}$ network infrastructure, such as iron towers, optical cables, power supplies, 5G technology to transform the existing highway network to make it a super highway, use digital technology to transform existing energy transform the backbone network to promote the intelligent upgrade of the energy system; use digital technology to transform the public

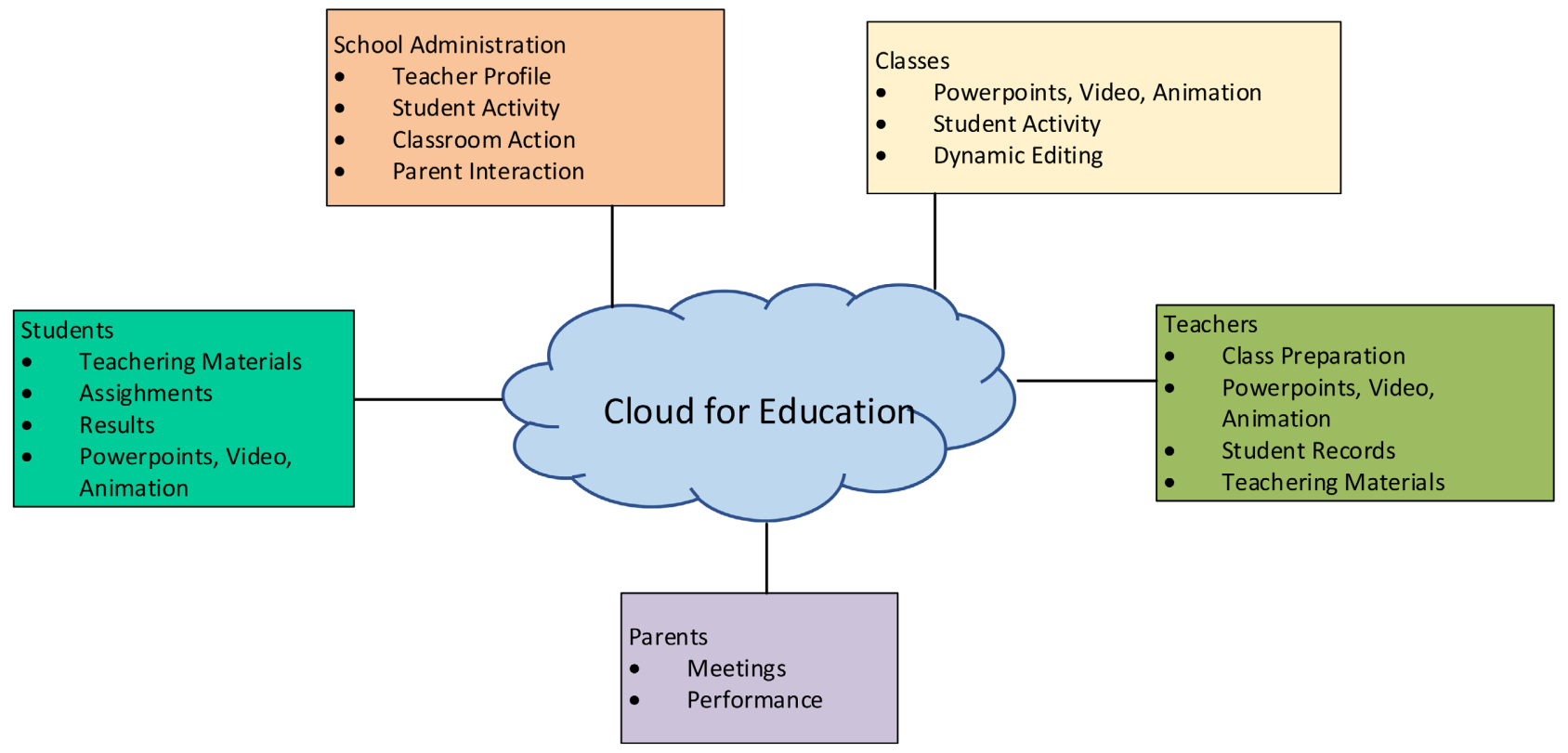

Figure 2. Example of a cloud for education with different interactions under new infrastructure. 
infrastructure of the city, so that it can realize resource sharing on the basis of retaining its own functions, and rely on the digital platform to realize various resources and functions. Organic fusion.

The new round of infrastructure construction has a strong scientific and technological flavor, featuring intelligence, informatization, and digitization, breaking through the traditional infrastructure model represented by railways and highways, not only catering to the current economic development trend, but also It has a major historical turning point.

\section{Educational Digital Resources Based on Block Chain}

In this framework, various educational institutions jointly create and maintain a blockchain platform, which is used to record, share and verify the achievements of each educational institution's discipline construction, scientific research, professional training, as well as learner information, academic achievements, etc., academic certificate, qualification certification, skill appraisal and honor recognition, etc. The blockchain-based education digital resource transaction guarantee model takes the blockchain network as the core to form a blockchain-based data sharing scheme. The main participants of the network are individual learners and educational institutions.

\subsection{Large-Scale Digital Educational Resources Based on Blockchain}

How to accurately represent all the data information in the process of data sharing in the form of data, and how to design a large-scale educational database and storage block can not only effectively ensure the security of the large-scale educational database, but also it can effectively guarantee the accuracy and authenticity of its data information.

These problems need to design and implement a blockchain-based, sharing-oriented data storage structure through comprehensive analysis and consideration of the storage structure of all data in the blockchain, as well as the data storage structure for resource transactions. The question in the blockchain-based digital education resource guarantee scheme: how to store the data that needs to be guaranteed in the blockchain and achieve distributed data consistency? In fact, this process is the process of data uploading. This problem requires comprehensive consideration of the storage structure of data in the blockchain, the data block structure for data resource protection, and the data type structure required by different consensus protocols in the blockchain.

\subsection{The Blockchain-Based Decentralized Large-Scale Digital Educational Resource Security Guarantee Solution}

The blockchain-based decentralized large-scale digital educational resource security guarantee solution needs to solve three important problems.

- First, the structural design of large-scale educational databases, including the storage form and storage location of large-scale educational data, the digital 
representation of the entire process of data information from input to sharing, and the security and integrity of large-scale educational databases and educational information. Performance and availability guarantees.

- Secondly, the distributed consistency of the data to be guaranteed, that is, how to achieve the consistency of the data that needs to be guaranteed in a decentralized environment.

- Third, the trusted interaction and data sharing of data resources, including the retrieval method of shared data information in the blockchain, the response and authorization of the data owner to the access request of the data requester, and the data information to be shared. Secure transactions with delivery.

To this end, it is necessary to comprehensively design the blockchain data storage structure and the data block structure oriented to resource transactions, realize the data storage structure based on blockchain and sharing-oriented, solve the problem of digital storage of educational resources, and ensure the digital education resources. Security, integrity and usability.

\subsection{The Blockchain-Based Education Digital Resource Transaction Guarantee}

The blockchain-based education digital resource transaction guarantee is based on the basic structure of the blockchain. The overall structure is composed of data sources, data owners, data requesters, blockchain networks, and resource retrieval systems. The reconstruction of learning space and the reshaping of learning scenarios in the digital age will break through the boundaries of traditional education and promote interdisciplinary knowledge research.

The Horizon Report has mentioned many times that the learning space is redesigned, focusing on the use of information technology to reconstruct and connect the real physical teaching space and the network virtual teaching space, adapt to the diverse learning methods of learning individuals and groups, and break through traditional teaching methods. Educational boundaries. Reconstructing the learning space and reshaping the learning scene, then transforming the main teachers of the learning space into students, breaking through to the gathering of students from different regions, disciplines, and ages, and the learning method will also change from the teacher's single preaching, career and confusion to teachers and students normalized cooperation, communication, exchanges and seminars from multiple parties.

Build a digital twin of educational subjects, and use learning measurement technology to achieve quantitative to qualitative changes in educational modernization. This development trend mainly describes a series of scientific techniques for quantitative assessment and evaluation of teachers and other students, and is widely used in the evaluation, measurement and recording of various school education researchers. The methods and means used for different types of educational needs such as learning preparation, learning progress, and skill acquisition at different stages. The use of big data analysis, machine learning, artificial 
intelligence and other technologies to measure and evaluate the whole process of learning will start the journey of educational modernization from quantitative change to qualitative change.

\section{Conclusion}

Digital education resources and intelligent supply help the intelligent supply of open education resources, create a sustainable knowledge innovation model, and form a human group wisdom sharing ecology. In the digital age, the interconnection of all things has restructured all production relations, giving birth to new enterprise production models, and more and more cross-industry institutions and cross-departmental cooperation. As the campus has gradually developed into an innovation of educational digital resources, it is widely believed that digitalization is an important way to promote innovation, and this development trend will provide methods and approaches for realizing digital educational resources and intelligent supply.

\section{Conflicts of Interest}

The author declares no conflicts of interest regarding the publication of this paper.

\section{References}

Abdullayev, A. A. (2020). System of Information and Communication Technologies in the Education. Science and World International Scientific Journal, 2, 19-21.

Alshare, K. A., Lane, P. L., \& Lane, M. R. (2018). Information Security Policy Compliance: A Higher Education Case Study. Information \& Computer Security, 26, 91-108. https://doi.org/10.1108/ICS-09-2016-0073

Cornetta, G., Mateos, J., Touhafi, A., \& Muntean, G.-M. (2019). Design, Simulation and Testing of a Cloud Platform for Sharing Digital Fabrication Resources for Education. Journal of Cloud Computing, 8, Article No. 12. https://doi.org/10.1186/s13677-019-0135-x

Dwivedi, Y. K., Hughes, D. L., Coombs, C., Constantiou, I., Duan, Y., Edwards, J. S. et al. (2020). Impact of COVID-19 Pandemic on Information Management Research and Practice: Transforming Education, Work and Life. International Journal of Information Management, 55, Article ID: 102211. https://doi.org/10.1016/j.ijinfomgt.2020.102211

Ezenwoke, A., Omoregbe, N., Ayo, C. K., \& Edwards, J. S. (2013). NIGEDU CLOUD: Model of a National E-Education Cloud for Developing Countries. IERI Procedia, 4, 74-80. https://doi.org/10.1016/j.ieri.2013.11.012

Gu, T., Zhang, P., \& Zhang, X. (2021). Spatio-Temporal Evolution Characteristics and Driving Mechanism of the New Infrastructure Construction Development Potential in China. Chinese Geographical Science, 31, 646-658.

https://doi.org/10.1007/s11769-021-1214-8

Ju, D., \& Shen, B. (2011). On Building Knowledge Cloud. In Proceedings of 2011 International Conference on Computer Science and Service System (pp. 2351-2353). Institute of Electrical and Electronics Engineers. https://doi.org/10.1109/CSSS.2011.5975064

Kudinov, I. V., Kudinova, G. F., Aitov, V. F., \& Kadi, S. V. (2018). Information Technol- 
ogies in Professional Pedagogical Education. International Journal of Mechanical Engineering and Technology, 9, 1284-1292.

Kweon, E., Lee, H., Chai, S., \& Yoo, K. (2021). The Utility of Information Security Training and Education on Cybersecurity Incidents: An Empirical Evidence. Information Systems Frontiers, 23, 361-373. https://doi.org/10.1007/s10796-019-09977-Z

Lergetporer, P., Schwerdt, G., Werner, K., West, M. R., \& Woessmann, L. (2018). How Information Affects Support for Education Spending: Evidence from Survey Experiments in Germany and the United States. Journal of Public Economics, 167, 138-157. https://doi.org/10.1016/j.jpubeco.2018.09.011

Masud, M. D. A. H., Yong, J., \& Huang, X. (2012). Cloud Computing for Higher Education: A Roadmap. In Proceedings of the 2012 IEEE 16th International Conference on Computer Supported Cooperative Work in Design (pp. 552-557). Institute of Electrical and Electronics Engineers. https://doi.org/10.1109/CSCWD.2012.6221872

Mkrttchian, V., Kataev, M., Shih, T. K., Kumar Misra, P., \& Fedotova, A. (2014). Avatars "HHH" Technology Education Cloud Platform on Sliding Mode Based Plug-Ontology as a Gateway to Improvement of Feedback Control Online Society. International Journal of Information Communication Technologies and Human Development, 6, 13-31. https://doi.org/10.4018/ijicthd.2014070102

Nie, W., Xiao, X., Wu, Z., Wu, Y., Shen, F., \& Luo, X. (2018). The Research of Information Security for the Education Cloud Platform Based on AppScan Technology. In Proceedings of 2018 5th IEEE International Conference on Cyber Security and Cloud Computing/ 2018 4th IEEE International Conference on Edge Computing and Scalable Cloud (pp. 185-189). Institute of Electrical and Electronics Engineers. https://doi.org/10.1109/CSCloud/EdgeCom.2018.00040

Park, N., Sung, Y., Jeong, Y., Shin, S.-B., \& Kim, C. (2018). The Analysis of the Appropriateness of Information Education Curriculum Standard Model for Elementary School in Korea. In R. Lee (Ed.), International Conference on Computer and Information Science (pp. 1-15). Springer. https://doi.org/10.1007/978-3-319-98693-7 1

Rustamova, N. R. (2019). Using of Vitagenic Technology in the Education System. Proceeding of the ICECRS, 3, 1-4.

Sheikh, A. Y., \& Fann, J. I. (2019). Artificial Intelligence: Can Information Be Transformed into Intelligence in Surgical Education? Thoracic Surgery Clinics, 29, 339-350. https://doi.org/10.1016/j.thorsurg.2019.03.011

Simões, C., \& Soares, A. M. (2010). Applying to Higher Education: Information Sources and Choice Factors. Studies in Higher Education, 35, 371-389.

https://doi.org/10.1080/03075070903096490

White, M. A. (2018). Information and Imagery Education. In M. A. White (Ed.), What Curriculum for the Information Age (pp. 41-66)? Routledge. https://doi.org/10.4324/9781315060255-3

Winkler, R., \& Söllner, M. (2018). Unleashing the Potential of Chatbots in Education: A State-of-the-Art Analysis. Proceedings 2018. https://doi.org/10.5465/AMBPP.2018.15903abstract

Wu, J., Zhang, Y., \& Shi, Z. (2021). Crafting a Sustainable Next Generation Infrastructure: Evaluation of China's New Infrastructure Construction Policies. Sustainability, 13, Article No. 6245. https://doi.org/10.3390/su13116245

Zamora-Polo, F., Luque Sendra, A., Aguayo-Gonzalez, F., \& Sánchez-Martín, J. (2019). Conceptual Framework for the Use of Building Information Modeling in Engineering Education. International Journal of Engineering Education, 35, 744-755. 